\title{
INDUCIBLE EXPRESSION OF BASIC TRANSCRIPTION ELEMENT-BINDING PROTEN 2 IN PROLIFERATING SMOOTH MUSCLE CELLS AT THE VASCULAR ANASTOMOTIC STRICTURE
}

Toshiro Ogata, MDa

Masahiko Kurabayashi, $\mathrm{MD}^{\mathrm{b}}$

Yo-ichi Hoshino, MD $^{\mathrm{b}}$

Ken-ichi Sekiguchi, $\mathrm{MD}^{\mathrm{b}}$

Susumu Ishikawa, MD

Yasuo Morishita, $\mathrm{MD}^{\mathrm{a}}$

Ryozo Nagai, $\mathrm{MD}^{\mathrm{b}}$
Objective: The proliferation of vascular smooth muscle cells surrounding a suture line is an important factor in the development of anastomotic stricture that is frequently seen after coronary artery bypass grafting. The aim of this study was to investigate the time course of intimal thickening and to examine the expression of the molecular marker of smooth muscle cell activation surrounding the suture line.

Methods: Longitudinal aortotomy was performed in the abdominal aorta of rats. The rats were put to death 1,2, 4, and 8 weeks after aortotomy, and the percentage of the lumen occluded by intimal thickening was calculated. All tissues were stained with antibodies against basic transcription elementbinding protein 2, human cyclin-dependent kinase (cdk4), and Sp1 for immunohistochemistry. Basic transcription element-binding protein 2 is a transcription factor that is involved in phenotypic modulation of vascular smooth muscle cells. Cdk4 represents a marker for $G_{1}$ phase of the cell cycle. $\mathrm{Sp} 1$ is a transcription factor known to be expressed in a variety of tissues. Basic transcription element-binding protein 2 messenger RNA expression was confirmed by means of reverse transcriptase-polymerase chain reaction.

Results: We noted significant thickening of the intimal layer 1 week after aortotomy. Immunohistochemistry demonstrated that smooth muscle cells in the neointima were strongly positive for basic transcription element-binding protein 2 and human cyclin-dependent kinase 4, which peaked 2 weeks after aortotomy. Basic transcription element-binding protein 2 expression was closely associated with human cyclin-dependent kinase 4 expression in the neointima, although Sp1 was not. Basic transcription element-binding protein 2 messenger RNA levels were significantly up-regulated early after aortotomy.

Conclusion: The experimental rat aortotomy model is useful to investigate the proliferation of vascular smooth muscle cells around the suture line. Moreover, our results suggest the possible role of basic transcription element-binding protein 2 in the development of vascular anastomotic strictures. (J Thorac Cardiovasc Surg 2000;119:983-9)
From the Second Department of Surgery and the Second Department of Internal Medicine, ${ }^{\mathrm{b}}$ Gunma University School of Medicine, Maebashi, Gunma, Japan.

Supported by a grant-in-aid of the Ministry of Education, Science, and Culture of Japan.

Received for publication April 5, 1999; revisions requested May 27, 1999; revisions received Nov 10, 1999; accepted for publication Dec 7, 1999.

Address for reprints: Ryozo Nagai, MD, Second Department of Internal Medicine, Gunma University School of Medicine, 3-3922 Showa-machi, Maebashi City, Gunma 371-8511, Japan.

Copyright $@ 2000$ by The American Association for Thoracic Surgery $0022-5223 / 2000 \$ 12.00+0 \quad \mathbf{1 2 / 1 / 1 0 4 8 7 1}$

doi: $10.1067 / \mathrm{mtc} .2000 .104871$
$\Delta$ utologous saphenous vein grafts continue to be traAditionally used conduits for coronary revascularization. However, $25 \%$ to $31 \%$ of grafts are totally occluded or stenotic at 5 years, and $48 \%$ to $66 \%$ are totally occluded at more than 10 years after coronary artery bypass grafting (CABG). ${ }^{1,2}$ On the other hand, arterial grafts, such as an internal thoracic artery, are superior to the saphenous vein grafts in late patency. ${ }^{1}$ Nonetheless, $10 \%$ to $23 \%$ of grafts still show evidence of occlusion or stenosis at 5 years. ${ }^{3}$

The success of CABG depends on many factors, including technical aspects. Surgical preparation, such 


\section{$\mathrm{I} / \mathrm{M}$ ratio}

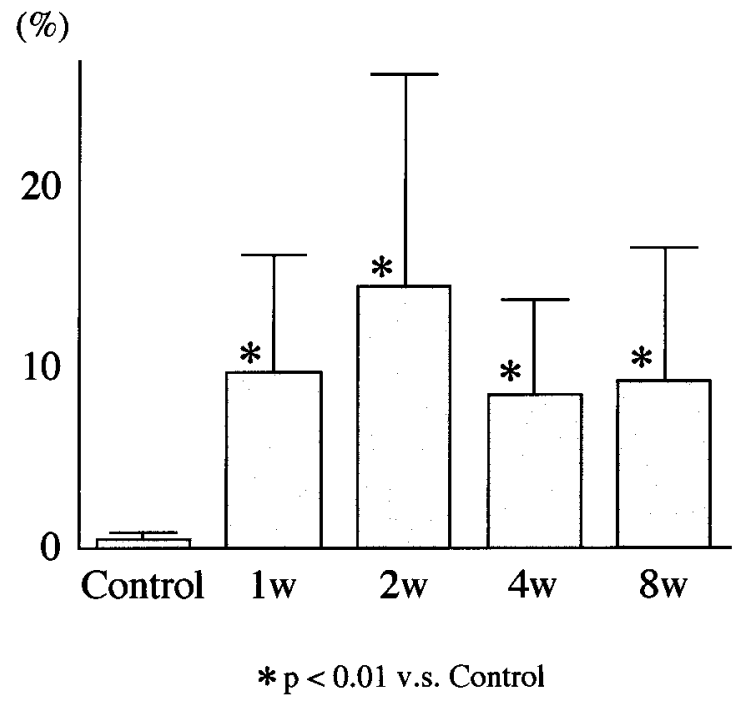

Fig 1. The I/M ratio on the suture line. Significant thickening of the intimal layer was seen 1 week after aortotomy, and it peaked at 2 weeks. These values were not statistically different within the injured groups but significantly $(P<.01)$ increased in the injured groups compared with the control animals. Values were expressed as mean \pm SD.

as direct mechanical trauma or luminal distention, leads to medial and endothelial damage. ${ }^{4}$ Occlusion or stenosis may result from early vascular wall ischemia as a result of poor early perfusion of the vasa vasorum. ${ }^{5}$ The vascular geometry has been described as a risk factor in atherogenesis. ${ }^{6}$ Moreover, intimal thickening around a suture line, although technically nonpreventable, is also an important factor in the development of a vascular anastomotic stricture after CABG. This condition has been shown to occur preferentially at the heel and toe of the junction and at the suture line in the anastomosis configuration early after graft implantation, gradually increasing particularly at the toe portion of anastomosis. ${ }^{7-9}$ Later, the intimal thickening increases excessively, and severe luminal stenosis develops. ${ }^{9}$ These phenomena may be caused by the invasion and proliferation of smooth muscle cells (SMCs), fibroblasts, and matrix materials derived from the cut end of the host artery. ${ }^{10-12}$

Although a number of genes are differentially expressed between proliferating and quiescent vascular SMCs, the transcription factors that play a role in this process remain largely unknown. We have recently demonstrated that basic transcription element-binding protein 2 (BTEB2), guanine cytosine (GC) box-binding zinc finger protein, is a transcription factor regulat- ing the SMemb gene, which is also known as the nonmuscle myosin heavy chain-B isoform gene. ${ }^{13}$ Our recent experiments have demonstrated that BTEB2 expression is down-regulated during aortic development and is reinduced after balloon injury. ${ }^{13,14}$ Expression of transcription factors, such as BTEB2, in proliferating vascular SMCs at the anastomosis remains to be investigated.

The aim of this study was to investigate the time course of intimal thickening and to examine the expression of the molecular marker of SMC activation surrounding a suture line by using a simple animal model as a substitute for a vascular anastomotic stricture.

\section{Material and methods}

Antibodies. We developed a monoclonal antibody against human BTEB2 by using an oligopeptide. ${ }^{13}$ Monoclonal antibody against human $\alpha$-smooth muscle actin (SM $\alpha$-actin) was purchased from DAKO A/S. Two polyclonal antibodies against human cyclin-dependent kinase $4(\operatorname{cdk} 4)$ and Sp1 were purchased from Santa Cruz Biotechnology, Inc. These antibodies were used for immunohistochemistry.

Animals. Adult male Wistar rats weighing 150 to $200 \mathrm{~g}$ were used in this study. They were housed under conventional conditions and fed a standard diet and water. Rats were purchased from Charles River Co. The protocol of this investigation was approved by the Institutional Committee for the Care and Use of Laboratory Animals in Gunma University School of Medicine.

Rat aortotomy model. Rats were anesthetized with sodium pentobarbital (30 mg/kg body weight) administered by means of intraperitoneal injection. The abdominal aorta was exposed from below the renal arteries to just above the aortic bifurcation through a midline incision in the abdomen. The abdominal aorta was clamped, and a longitudinal aortotomy $(5 \mathrm{~mm}$ in length) was made. The wound was immediately closed by using a continuous suture of 9-0 monofilament nylon without disturbing the intima. After confirmation of patency and the absence of bleeding, the abdominal wall was closed in layers.

Euthanasia. In the injured groups rats were put to death 1, 2,4 , and 8 weeks after aortotomy. In the control group rats were put to death without aortotomy. The aortas were perfusion fixed in situ with $10 \%$ (wt/vol) buffered formalin $(\mathrm{pH}$ 7.4) at $100 \mathrm{~mm} \mathrm{Hg}$ after infusion of saline solution containing heparin $(20 \mathrm{U} / \mathrm{mL}$, Shimizu Pharmaceutical Co) administered through a cannula placed in the left ventricle. They were then removed and placed in $10 \%$ buffered formalin for further fixation. The central parts of the excised vessel were embedded in paraffin, and 3- $\mu \mathrm{m}$ cross sections were prepared.

Evaluation of intimal thickening. Serial sections from tissue were stained with hematoxylin and eosin and elastica to indicate the intima and internal elastic lumina. The intimal and medial cross-sectional areas were calculated blindly by using an imaging analysis system. The ratio of intimal to medial cross-sectional areas (I/M ratio) was also determined 


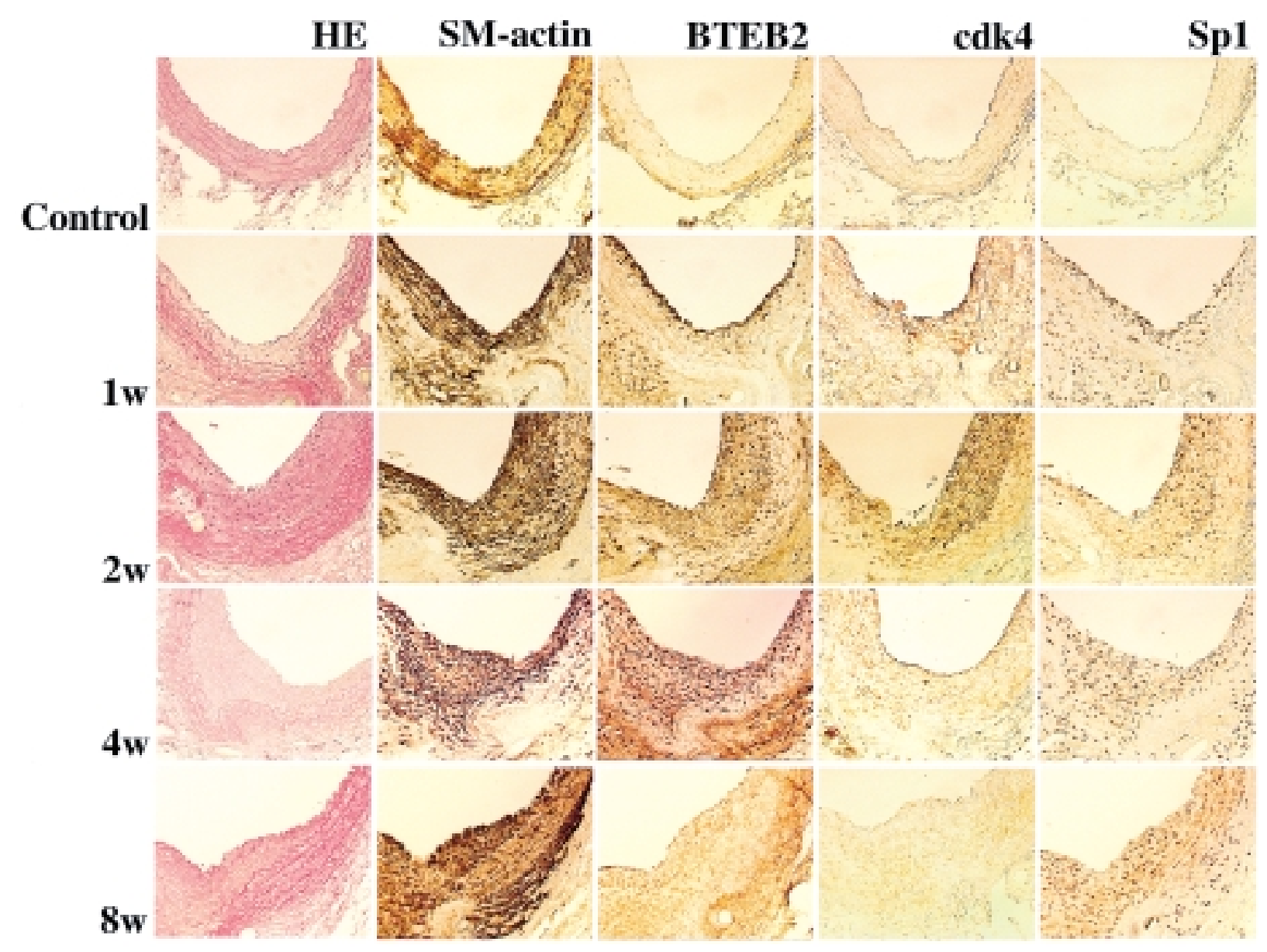

Fig 2. Photomicrographs of the immunohistochemistry of developing aorta (original magnification $\times 200$ ). In control animals no evident staining of BTEB2, cdk4, or Sp1 was detected in any layer, although SM $\alpha$-actin staining was observed in the medial layer of aorta. After aortic injury, neointimal cells were extensively stained with antiSM $\alpha$-actin antibody, indicating proliferation of SMCs. SM $\alpha$-actin staining was observed in both the intimal and the medial layer of the aorta and even in the adventitia 1, 2, 4, and 8 weeks after aortotomy. We found BTEB2and cdk4-positive SMCs in the neointima 1 week after aortotomy. These levels peaked at 2 weeks, and SMCs were strongly positive for BTEB2 and cdk4 in the neointima. Only a few cells beneath the internal elastic lamina were positive for BTEB2 and cdk4 in the media. BTEB2-positive cells were also observed in the adventitia around the suture, where $\mathrm{SM} \alpha$-actin-positive cells were present. Sp1 was expressed in the neointima but not necessarily localized to the neointimal SMCs. Sp1-positive cells existed during the entire duration of injury.

blindly by using an imaging analysis system (Adobe Photoshop 5.0J, NIH Image 1.61/ppc).

Immunohistochemical analysis. All tissues were stained with antibodies against BTEB2, SM $\alpha$-actin, cdk4, or Sp1. BTEB2 is a transcription factor that is involved in phenotypic modulation of vascular SMCs. ${ }^{13,14} \mathrm{SM} \alpha$-actin is an isoform of smooth muscle actin and represents a marker for myoblasts and SMCs. ${ }^{15,16} \mathrm{Cdk} 4$ was used as a marker for DNA synthesis of vascular SMCs in this study. The synthesis of cyclin D1 and its assembly with cdk4 to form an active complex is a rate-limiting step in progression through the $\mathrm{G}_{1}$ phase of the cell cycle. ${ }^{17} \mathrm{Sp} 1$ is known to be expressed in a variety of tissues ${ }^{18}$ and is potentially a crucial transcription factor for the expression of many genes. ${ }^{19}$ Immunoenzymatic staining was carried out by using a Vectastatin Elite ABC Kit (Vector Laboratories). Sections were preincubated in methanol containing $0.3 \%$ hydrogen peroxide for 30 minutes and blocked with Protein Blocking Serum Free (Dako Corp) solution for 15 minutes to reduce nonspecific reactions. Antibodies against BTEB2 (1:4000), SM $\alpha$-actin (1:50), cdk4 $(1: 100)$, and $\operatorname{Sp} 1(1: 100)$ were applied and incubated for 30 minutes at room temperature. Sections were incubated with biotinyl-labeled immunoglobulins for 30 minutes and then incubated with horseradish peroxidase-labeled streptavidin 
$(\%)$

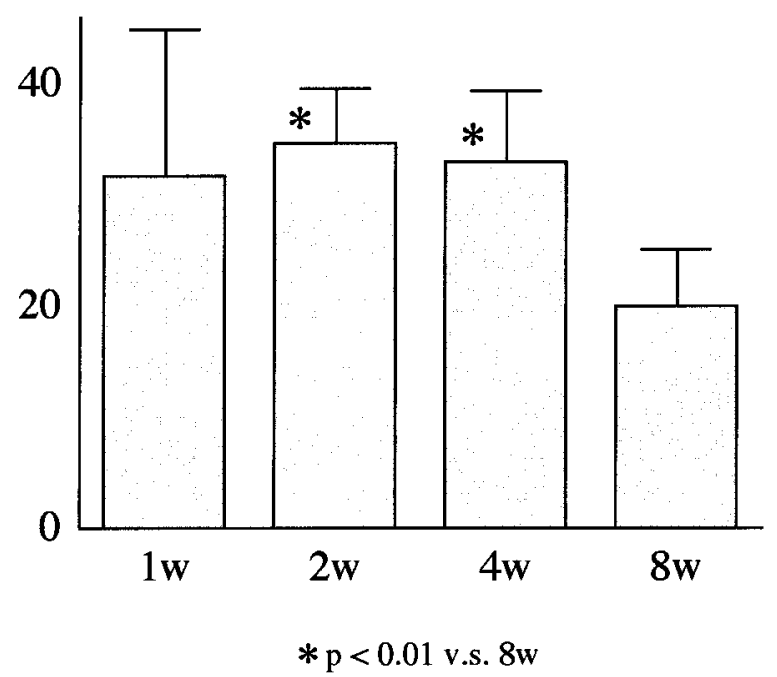

Fig 3. The percentage of BTEB2-labeled cells. The percentage of BTEB2-labeled cells in neointima peaked at 2 weeks and gradually declined thereafter. These values were significantly $(P<.01)$ decreased at 8 weeks compared with 2 or 4 weeks. Values were expressed as mean \pm SD.

solution for 30 minutes. Peroxidase activity was revealed by 3,3'-diaminobenzidine tetrahydrochloride $(0.2 \mathrm{mg} / \mathrm{mL}$, Sigma Chemical Co) with hydrogen peroxide $(0.015 \%)$. The sections were counterstained with methyl green, dehydrated, and mounted.

Percentage of BTEB2-labeled cells. The percentage of BTEB2-labeled cells in neointima was evaluated at each time point (labeled cells/total cells $\times 100$ ). Cells were counted as positive for BTEB2 when distinctly stained for immunohistochemistry.

Reverse transcription-polymerase chain reaction Southern blot analysis. BTEB2 transcripts were evaluated by using reverse transcription-polymerase chain reaction (RT-PCR) Southern blot analysis for normal control aortas and aortas at 1 and 2 weeks after aortotomy. Aortas were harvested and immediately fixed with liquid nitrogen, and total RNA was prepared by using the acid guanidinium thiocyanate-phenol-chloroform method (ISOGEN, Nippon Gene). Aliquots of RNA derived from aortas were amplified simultaneously by PCR ( 35 cycles) with rat BTEB2 2 primers ${ }^{14}$ or reduced glyceraldehyde-phosphate dehydrogenase (GAPDH) primers. PCR products were subjected to electrophoresis through $2 \%$ agarose gels stained with ethidium bromide. Fragments were blotted to a nylon membrane (Hybond $\mathrm{N}^{+}$, Amersham), and the specificity of gene amplifications was confirmed by means of Southern blot analysis. Hybridization was performed with isotope-labeled rat BTEB2 complementary (c)DNAs ${ }^{14}$ and GAPDH cDNAs (Ready-To-Go DNA labeling Kit [-dCTP], Pharmacia
Biotech). The radioactivity of corresponding bands was quantified by using a FUJIX BIO-Imaging Analyzer BAS 2000 (Fuji Photo Film). BTEB2 messenger (m)RNA levels were normalized to GAPDH mRNA levels by calculating the ratio of BTEB2 mRNA/GAPDH mRNA radioactivity for each sample.

Statistical analysis. All values were expressed as means \pm SD. Statistical comparisons were performed with a commercially available statistical package for the Macintosh personal computer (STAT VIEW-J5.0, Abacus Concepts). Data were analyzed with analysis of variance for multiple comparisons. If a significant $P$ value was present, the Bonferroni correction was used to identify specific intergroup differences.

\section{Results}

Evaluation of intimal thickening. Rats were randomly separated into 4 injured groups after aortotomy ( $n=15$ in each group). Six rats of the injured group were excluded from observation because of retroperitoneal abscess $(n=3)$ and unknown cause of death $(\mathrm{n}=3)$. The control rats were killed without aortotomy $(\mathrm{n}=15)$.

We found significant thickening of the intimal layer 1 week after aortotomy (Fig 1). Values of I/M ratio were $9.8 \% \pm 6.5 \%(\mathrm{n}=13), 14.5 \% \pm 11.8 \%(\mathrm{n}=14)$, $8.4 \% \pm 5.3 \%(\mathrm{n}=15)$, and $9.2 \% \pm 7.4 \%(\mathrm{n}=12)$ at 1 , 2,4 , and 8 weeks after aortotomy, respectively, in the injured groups and $0.5 \% \pm 0.3 \%(\mathrm{n}=15)$ in the control group. These values were not statistically different throughout the injured groups but increased significantly in the injured groups compared with the control animals $(P=.003, P=.0001, P=.007$, and $P=.005$, respectively).

Immunohistochemical analysis. Immunohistochemistry was performed by use of antibodies to BTEB2, SM $\alpha$-actin cdk4, and Sp1 (Fig 2). Our results demonstrated that SMCs in the neointima were strongly positive for BTEB2 and cdk4, which peaked 2 weeks after aortotomy. BTEB2 expression was closely associated with cdk4 expression in the neointima, although Sp1 was not.

Percentage of BTEB2-labeled cells. The percentage of BTEB2-labeled cells in neointima was evaluated for each time point (Fig 3). The percentage peaked at 2 weeks after aortotomy and gradually declined thereafter. Values were $31.7 \% \pm 13.2 \%(\mathrm{n}=13), 34.6 \% \pm$ $5.0 \%(\mathrm{n}=14), 32.9 \% \pm 6.4 \%(\mathrm{n}=15)$, and $20.0 \% \pm$ $5.0 \%(\mathrm{n}=12)$ at $1,2,4$, and 8 weeks after aortotomy, respectively. These values decreased significantly at 8 weeks after injury compared with 2 weeks $(P=.0002)$ or 4 weeks $(P=.003)$ after injury.

RT-PCR Southern blot analysis. The rats were randomly separated into two injured groups after aortoto- 


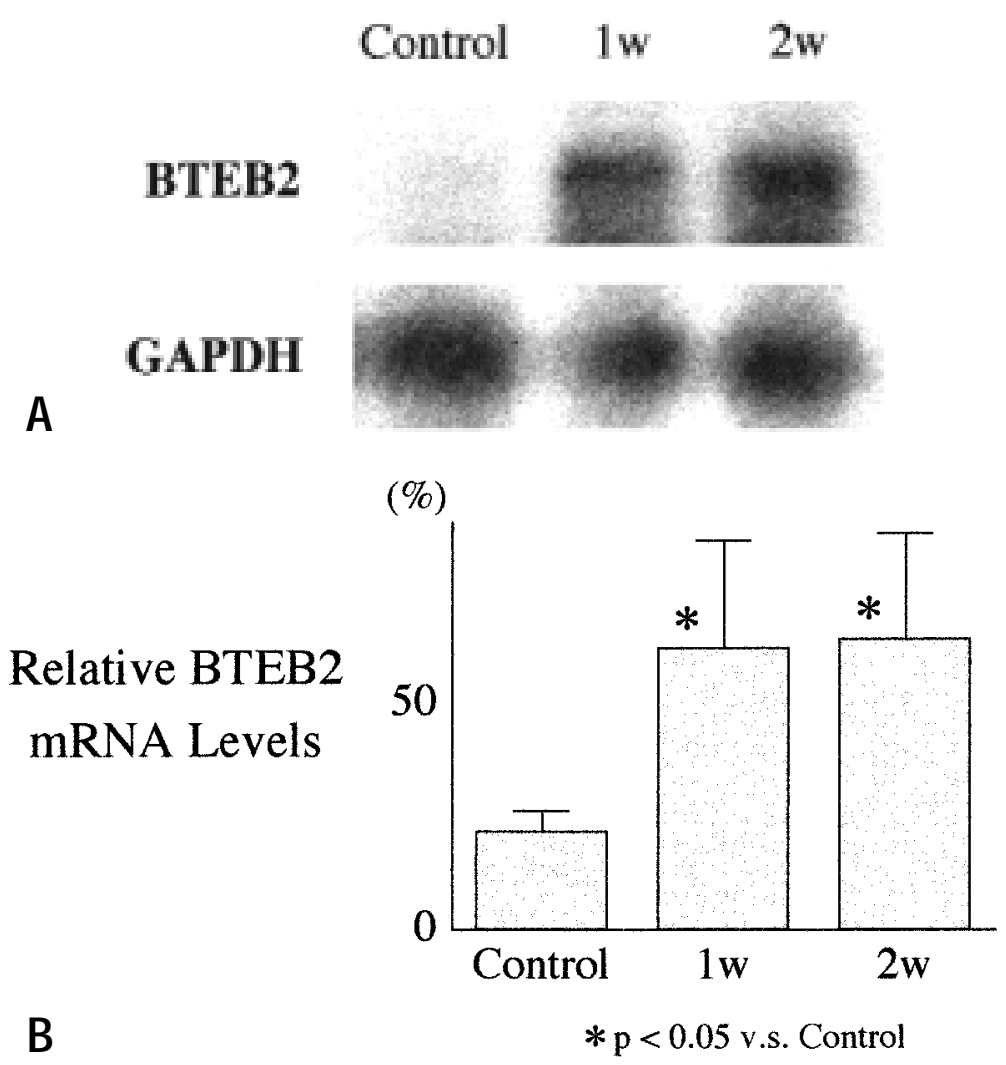

Fig 4. BTEB2 mRNA levels early after aortotomy by RT-PCR and Southern blot analyses. A, Autoradiograms of Southern blot analysis of PCR products. BTEB2 and GAPDH mRNAs from normal control aortas and aortas 1 and 2 weeks after aortotomy were amplified by RT-PCR. B, Summary of the quantitative changes in relative BTEB 2 mRNA expression levels. These values were significantly $(P<.05)$ higher at 1 or 2 weeks compared with the control animals. Values were expressed as mean \pm SD.

my ( $\mathrm{n}=3$ in each group). The control rats were killed without aortotomy $(\mathrm{n}=3)$. BTEB2 mRNA expression early after aortotomy was confirmed by means of RTPCR and Southern blot analyses (Fig 4, A). BTEB2 mRNA levels were evaluated for normal control aortas and aortas at 1 week and 2 weeks after aortotomy. Relative BTEB2 mRNA levels were quantified, and their values were $21.5 \% \pm 5.0 \%$ for the control rats and $61.9 \% \pm 23.8 \%$ and $63.9 \% \pm 23.3 \%$ at 1 and 2 weeks after aortotomy, respectively. These values were significantly higher at 1 week $(P=.04)$ or 2 weeks $(P=.03)$ compared with the control rats (Fig 4,B).

\section{Discussion}

The proliferation of vascular SMCs surrounding a suture line is an important factor in the development of a vascular anastomotic stricture that is frequently noted after CABG. We have recently identified BTEB2 as a transcription factor regulating the expression of the SMemb gene, which is involved in the phenotypic mod- ulation of vascular SMCs. In the present study we investigated the expression of BTEB2 by using an aortotomy model, which could be substituted for a vascular anastomotic stricture. BTEB2 expression increased in the neointimal layer accompanying the development of intimal thickening, and BTEB2 mRNA expression was also confirmed by means of RT-PCR. Moreover, BTEB2 expression was closely associated with cdk4 expression in the neointima, although Sp1 expression was not. Thus our results suggest that BTEB2 plays a potential role in the development of vascular anastomotic strictures.

We used the aortotomy model because intimal thickening is regularly observed after this procedure. In contrast to previous experimental models of vascular anastomotic stricture in which an end-to-end or an end-to-side anastomosis was performed,,${ }^{9,20,21}$ our model readily allowed us to measure the intimal thickening at the suture line. The proliferation of vascular SMCs around the suture line was remarkable in the sense that the $\mathrm{I} / \mathrm{M}$ ratio increased as rapidly as is seen 
after balloon injury. ${ }^{22,23}$ The time course of intimal thickening after aortotomy was comparable with that reported in balloon injury models. ${ }^{22,23}$

Identification of transcription factors that are specifically activated in response to vascular injury is important for investigation of the molecular mechanisms responsible for development of anastomotic stenosis after CABG. The GC-rich sequence, the so-called GC box, is an important transcriptional regulatory element in the promotions of many mammalian genes. ${ }^{24,25}$ As a factor binding to the GC box, Sp1 was first identified and was shown to be an important component for the basal transcriptional machinery. ${ }^{19,26}$ Recently, several members of Krüppellike transcription factors, including BTEB2, erythroid Krüppel-like factor (EKLF), and lung Krüppel-like factor (LKLF), have been cloned and characterized as GC box-binding factors. ${ }^{27,28}$ These proteins and Sp1 commonly contain 3 contiguous $\mathrm{Cys}_{2}-\mathrm{His}_{2}$ zinc finger motifs at their C-terminal region as a DNA-binding domain. ${ }^{29}$ We have recently identified a cDNA clone encoding GC box-binding zinc finger protein BTEB2 as a transcription factor regulating the $S M e m b$ gene, also known as the nonmuscle myosin heavy chain-B isoform gene. ${ }^{13}$ Our initial in vitro experiments have indicated that BTEB2 is preferentially expressed in proliferating vascular SMCs and that BTEB2 mRNA levels are rapidly increased on mitogenic stimulation. ${ }^{13}$ We have also demonstrated positive staining for BTEB2 in the neointimal layer of balloon-injured aorta. ${ }^{14}$ Therefore we have postulated that BTEB2 may play a regulatory role in activated vascular SMCs. Likewise, the present study suggests that BTEB2 could promote the proliferation of vascular SMCs around the suture line formed in an aortotomy model, which could substitute for an anastomotic stricture.

In summary, a simple experimental rat aortotomy model was proved to be useful in the examination of intimal thickening surrounding the suture line. This model may be suitable in studies of acute reaction rather than chronic change of the vascular anastomotic stricture. Moreover, our results suggest that the induced expression of BTEB2 may play an important role in stimulating SMC proliferation and a possible role in vascular anastomotic strictures. Further studies should be directed toward elucidating the function of BTEB2 in vascular anastomotic strictures by suppressing its expression through an antisense strategy.

We thank Mrs Yoshiko Nonaka for technical help.

\section{REFERENCES}

1. FitzGibbon GM, Kafka HP, Leach AJ, Keon WJ, Hooper GD, Burton JR. Coronary bypass graft fate and patient outcome: angiographic follow-up of 5065 grafts related to survival and reoperation in 1388 patients during 25 years. J Am Coll Cardiol 1996;28:616-26.

2. Bourasa MG, Fischer LD, Campeau L, Gillespie MJ, McConney M, Lesperance J. Long-term fate of bypass graft: the coronary artery surgery study (CASS) and Montreal heart institute experiences. Circulation 1985;72(Suppl):V-71.

3. Mack MJ, Osborne JA, Shennib H. Arterial graft patency in coronary artery bypass grafting: What do we really know? Ann Thorac Surg 1998;66:1055-9.

4. Ramos JR, Berger K, Mansfield PB, Sauvage LR. Histological fate and endothelial changes of distended and nondistended vein grafts. Ann Surg 1976;183:205-28.

5. McGeachie J, Campbell P, Pendergrast F. Vein-to-artery grafts: a quantitative study of revascularization by vasa vasorum and its relationship to intimal hyperplasia. Ann Surg 1981;194:100-7.

6. Caro CG, Parker KH. The effect of hemodynamic factors on the arterial wall. In: Olsson AG, editor. Atherosclerosis—biology and clinical science. Edinburgh: Churchill Livingstone; 1987. p. 183-95.

7. Bassiouny HS, White S, Glagov S, Choi F, Giddens DP, Zarins CK. Anastomotic intimal hyperplasia: mechanical injury or flow induced. J Vasc Surg 1992;15:708-17.

8. Sottiurai VS, Yao JST, Baston RC, Sue SL, Jones R, Nakamura YA. Distal anastomotic intimal hyperplasia: histological character and biogenesis. Ann Vasc Surg 1989;3:26-33.

9. Shiroma H, Kusaba A. Ultrastructural features of progressive intimal hyperplasia at the distal end-to-side anastomosis of vein grafts. Cardiovasc Surg 1996;4:393-8.

10. Unni KK, Kottke BA, Titus JL, Frye RL, Wallace RB, Brown AL. Pathologic changes in aortocoronary saphenous vein grafts. Am J Cardiol 1974;34:526-32.

11. Sottiurai VS, Yao JS, Filnn WR, Batson RC. Intimal hyperplasia and neointima; an ultrastructural analysis of thrombosed grafts in humans. Surgery 1983;93:809-17.

12. Clowes AW, Grown AM, Hanson SR, Reidy MA. Mechanisms of arterial graft failure; 1 : role of cellular proliferation in early healing of PTFE prosthesis. Am J Pathol 1985;118:43-54.

13. Watanabe N, Kurabayashi M, Shimomura Y, Kawai-Kowase K, Hoshino Y, Manabe I, et al. BTEB2, a Krüppel-like transcription factor, regulates expression of the SMemb/non-muscle myosin heavy chain B (SMemb/NMHC-B) gene. Circulation Res 1999;85:182-91.

14. Kawai-Kowase K, Kurabayashi M, Hoshino Y, Ohyama Y, Nagai $R$. Transcriptional activation of the zinc finger transcription factor BTEB2 gene by Egr-1 through mitogen-activated protein kinase pathways in vascular smooth muscle cells. Circ Res 1999;85:787-95.

15. Benzonana G, Skalli O, Gabbiani G. Correlation between the distribution of smooth muscle or non muscle myosin and $\alpha$-smooth muscle actin in normal and pathological soft tissues. Cell Motil Cytoskeleton 1988;11:260-74.

16. Darby I, Skalli O, Gabbiani G. $\alpha$-Smooth muscle actin in transiently expressed by myofibroblasts during experimental wound healing. Lab Invest 1990;63:21-9.

17. Kamb A, Gruis NA, Weaver-Feldhaus J, Liu Q, Harshman K, Tavtigian SV, et al. A cell cycle regulator potentially involved in genesis of many tumor types. Science 1994;264:436-40.

18. Saffer JD, Jackson SP, Annarella MB. Developmental expression of Sp1 in the mouse. Mol Cell Biol 1991;11:2189-99.

19. Kadonaga JT, Jones KA, Tjian R. Promoter specific activation of RNA polymerase transcription by Sp1. Trends Biochem Sci 1986;11:20-3. 
20. Lei M, Archie JP, Kleonstreuer C. Computational design of a bypass graft that minimizes wall shear stress gradients in the region of the distal anastomosis. J Vasc Surg 1997;25:637-46.

21. Ishibashi H, Sunamura M, Karino T. Flow patterns and preferred sites of intimal thickening in end-to-end anastomosed vessels. Surgery 1995;117:409-20.

22. Kocher O, Gabbiani F, Gabbiani G, Reidy MA, Cokay MS, Peters $\mathrm{H}$, et al. Phenotypic features of smooth muscle cells during the evolution of experimental carotid artery intimal thickening: biochemical and morphologic studies. Lab Invest 1991;65: 459-70.

23. Clowes AW, Reidy MA, Clowes MM. Kinetics of cellular proliferation after arterial injury: smooth muscle growth in the absence of endothelium. Lab Invest 1983;49:327-33.

24. Dynan W, Tjian R. Control of eukaryotic messenger RNA synthesis by sequence-specific DNA-binding proteins. Nature 1985;316:774-8.
25. Mitchell PJ, Tjian R. Transcriptional regulation in mammalian cells by sequence-specific DNA binding proteins. Science 1989;245:371-8.

26. Courey AJ, Tjian R. Analysis of Sp1 in vivo reveals multiple transcriptional domains, including a novel glutamine-rich activation motif. Cell 1987;55:887-98.

27. Anderson KP, Kern CB, Crable SC, Lingrel JB. Isolation of a gene encoding a functional zinc finger protein homologous to erythroid Kruppel-like factor: identification of a new multigene family. Mol Cell Biol 1995; 15:5957-65.

28. Sogawa K, Imataka I, Yamasaki Y, Kusume H, Abe H, FujiiKuriyama Y. cDNA cloning and transcriptional properties of a novel GC box-binding protein, BTEB2. Nucleic Acids Res 1993;21:1527-32.

29. Kojima S, Kobayashi A, Gotoh O, Ohkuma Y, Fujii-Kuriyama Y, Sogawa K. Transcriptional activation domain of human BTEB2, a GC box-binding factor. J Biochem 1997;121:389-96. 